\title{
Research on alloying technique of yttrium on AZ91D magnesium alloy
}

\author{
YULEI XU $\mathrm{XU}^{1,2, \mathrm{a}}$ and KUI ZHANG ${ }^{1, \mathrm{~b}}$ * \\ ${ }^{1}$ State Key Laboratory for Fabrication and Processing of Nonferrous Metals, General Research \\ Institute for Nonferrous Metals, Beijing 100088, China \\ ${ }^{2}$ School of Materials and Metallurgy, Inner Mongolia University of Science and Technology, Baotou \\ 014010, China \\ axuyulei@imust.cn, besuccessful@126.com
}

Keywords: Magnesium alloy; rare earth; die casting; alloying technique.

Abstract. Effect of alloying techniques of dollop-like yttrium, as-cast and extruded Mg-Y master alloy in AZ91D magnesium alloy on microstructure and the efficiency of alloying was studied by optical microscopy, scanning electron microscopy, XRD and inductively-coupled plasma (ICP) spectroscopy. The as-cast AZ91D-1.2wt.\%Y alloys were prepared and yttrium was added by different way at $750^{\circ} \mathrm{C}$ . The results showed that the efficiency of alloying achieved less than $50 \%$ within 60 minutes when dollop-like yttrium was added. When yttrium was added by as-cast and extruded Mg- $25 \mathrm{wt}$. \% Y master alloy, the efficiency of alloying was $71.3 \mathrm{wt}$. $\%$ and $78.3 \mathrm{wt}$. \%, respectively. The efficiency of alloying was improved because the Mg-Y master alloy could melt easily down at casting temperature. The $\mathrm{Mg}$-Y phases were formed in the $\mathrm{Mg}$-Y master alloys. After the as-cast $\mathrm{Mg}-\mathrm{Y}$ master alloy was extruded, the decrease in $\mathrm{Mg}$-Y particle size and increase in the number of nucleating sizes for $\mathrm{Mg}$ led to the microstructure of the as-cast AZ91D-1.15wt. \%Y alloy was refined.

\section{Introduction}

The magnesium alloy is the lightest constructional material, which has lower density, higher specific strength, higher specific stiffness, better electric conductivity, better cast characteristics than steel and aluminum alloys. The application of magnesium alloy in the automobile lightweight design is becoming more and more important $[1,2]$. However, the high working temperature of power train components can cause serious problems for traditional magnesium alloy application. AZ91D alloy cannot meet the demands of temperature beyond $120^{\circ} \mathrm{C}$ and high stress load $[3,4]$. It was reported that rare-earth metal $\mathrm{Y}$ could improve the heat resistance of magnesium alloy, because the high-melting point compounds $\mathrm{Al}_{2} \mathrm{Y}$ was formed and the grain was refined [5,6]. When the rare-earth metal $\mathrm{Y}$ added to as-cast $\mathrm{Mg}-\mathrm{Zr}-\mathrm{Zn}$ alloy, the grain was refined and $\mathrm{Mg}-\mathrm{Y}$ phase was formed so that the mechanical property of magnesium alloy was improved at the elevated temperature $[7,8]$.

For the AZ91D alloy, the typical die-casting temperature range of cold chamber die-casting machine is $650 \sim 680^{\circ} \mathrm{C}$, and that of hot chamber die-casting machine is 620 640 ${ }^{\circ} \mathrm{C}$ [9]. Due to the melting point of yttrium up to $1522^{\circ} \mathrm{C}$, yttrium is difficult to dissolve in the ordinary casting temperature. Therefore, in this work, the alloying techniques of yttrium in AZ91D were studied at conventional casting temperature, and the preparation technique of the Mg-Y master alloy was investigated. The efficiency of alloying was calculated when yttrium was added into magnesium alloy by the different way. The microstructure of magnesium alloy containing yttrium was observed by optical microscopy, scanning electron microscopy and XRD.

\section{Materials and experimental}

The raw materials used were commercial-grade AZ91D, industrial pure yttrium ingots and pure magnesium ingots.

The as-cast Mg-Y master alloys were prepared by the conventional casting method. The magnesium ingot was melted in a high-frequency melting furnace. Yttrium was added when the temperature of the 
molten was about $750^{\circ} \mathrm{C}$. Then the melt was refined by RJ-2 flux and cast into a permanent mould with a cavity of size $\Phi 90 \mathrm{~mm} \times 250 \mathrm{~mm}$. Furthermore, a part of the as-cast $\mathrm{Mg}$-Y master alloy was extruded by the extrusion machine after aging treatment carried at $550^{\circ} \mathrm{C}$ for $4 \mathrm{~h}$. The microstructure of as-cast and extruded Mg-Y master alloy was analyzed by optical microscopy and XRD.

The AZ91D magnesium alloy was melted in the crucible resistance furnace, using RJ-1 flux covering protection, and the crucible was heated to $750^{\circ} \mathrm{C}$. The surface of the dollop-like yttrium was polished smooth, and the weight of each one was $1.2 \%$ (mass percentage) of the melt. The dollop-like yttrium, as-cast and extruded $\mathrm{Mg}-\mathrm{Y}$ master alloys were added, respectively. The melt was held at 750 ${ }^{\circ} \mathrm{C}$ for $10 \mathrm{~min}$ and then poured into a permanent mould with a cavity of size $\Phi 90 \mathrm{~mm} \times 250 \mathrm{~mm}$. When the dollop-like yttrium was added, the melt was held for $30 \mathrm{~min}, 60 \mathrm{~min}, 90 \mathrm{~min}$, and $120 \mathrm{~min}$, respectively. The content of yttrium in master alloys determined by inductively-coupled plasma (ICP) spectroscopy is shown in table 1.

The microstructure of the part of the ingot in the middle and bottom sampling was observed. The advantages and disadvantages of different alloying methods were studied by the microstructures' analysis and component analysis.

The microstructure of alloys was characterized by the optical microscopy (Carl Zeiss Axiovert 200) and the scanning electron microscopy (HITACHI - S4800) equipped with an energy dispersive spectrometer (Oxford). The phases in the as-cast AZ91D containing yttrium were analyzed by D/Max-1200X type X-ray diffraction (XRD).

\section{Results and discussion}

\section{Efficiency of alloying at 750 으}

Table 1 summarized the efficiency of alloying when yttrium was added into AZ91D by different ways at $750^{\circ} \mathrm{C}$. The results show that the efficiency of alloying achieved less than $50 \%$ when the dollop-like yttrium was added into the melt held for $120 \mathrm{~min}$. The efficiency of alloying reached to $10.8 \%, 19.2 \%, 24.4 \%$ and $37.5 \%$ when the dollop-like yttrium was added into the melt held for 30 $\mathrm{min}, 60 \mathrm{~min}, 90 \mathrm{~min}$ and $120 \mathrm{~min}$, respectively. So it is difficult to achieve the desired alloy composition by directly adding dollop-like yttrium. However, the efficiency of alloying was around $71.3 \%$ and $78.3 \%$ when yttrium was added and held for $10 \mathrm{~min}$ by as-cast and extruded $\mathrm{Mg}-\mathrm{Y}$ master alloy, respectively.

Table 1 contents of yttrium of alloys

\begin{tabular}{lllll}
\hline Nominal alloys & $\begin{array}{l}\mathrm{Y} \\
{[\mathrm{mass} \%]}\end{array}$ & $\begin{array}{l}\text { Efficiency of } \\
\text { alloying [\%] }\end{array}$ & Addition type of Y & $\begin{array}{c}\text { Melt holding } \\
\text { time [min] }\end{array}$ \\
\hline AZ91D-1.2\%Y & 0.13 & 10.8 & Dollop-like & 30 \\
AZ91D-1.2\%Y & 0.23 & 19.2 & Dollop-like & 60 \\
AZ91D-1.2\%Y & 0.29 & 24.2 & Dollop-like & 90 \\
AZ91D-1.2\%Y & 0.45 & 37.5 & Dollop-like & 120 \\
AZ91D-1.15\% Y & 0.82 & 71.3 & As-cast master alloy & 10 \\
AZ91D-1.15\% Y & 0.90 & 78.3 & Extruded master alloy & 10 \\
\hline
\end{tabular}


Dollop-like yttrium was difficult to melt down at $750^{\circ} \mathrm{C}$ because yttrium melts at $1522^{\circ} \mathrm{C}$. The yttrium was dissolved by the diffusion or chemical reactions that produced the $\mathrm{Mg}-\mathrm{Y}$ intermetallic compounds with the lower melting point. When the master alloy was added into the molten, the $\mathrm{Mg}$ matrix molten down and the $\mathrm{Mg}$-Y phases with the higher melting point became some solid sphere of radius $(r)$ that accelerated downward under the influence of gravity. However, there were two addition forces, both acting upward: the constant buoyant force and a velocity-dependent retarding force given by Stokes' law. When the sum of the upward forces was equal to the gravitational force, the sphere traveled with a constant speed (V), called the sink rate. By Stokes' law, the sink rate is given by the relation

$$
\mathrm{v}=\frac{\mathrm{g}\left(\rho_{S}-\rho_{\mathrm{L}}\right) \mathrm{r}^{2}}{9 \eta} \text {. }
$$

Where $\rho_{S}$ and $\rho_{L}$ are the densities of the solid and liquid, respectively. The sink rate was influenced by solid sphere of radius $r$. Extruded $\mathrm{Mg}-\mathrm{Y}$ master alloy has resulted in significant refinement in $\mathrm{Mg}$-Y phase size so that the sink rate decreased, and the reaction or diffusion time was increased. The efficiency of alloying was improved.

\section{Microstructure of Mg-Y master alloy as-cast and extruded}

Figure 1 shows the microstructure of the $\mathrm{Mg}-25 \mathrm{wt} \% \mathrm{Y}$ master alloys. The microstructure of as-cast $\mathrm{Mg}-\mathrm{Y}$ master alloy was the primary $\alpha-\mathrm{Mg}$ and $\left(\alpha-\mathrm{Mg}+\beta-\mathrm{Mg}_{24} \mathrm{Y}_{5}\right)$ eutectic structure, as shown in figure 1(a). There was different shaped intermetallic phase, net-worked and isolated. The microstructure of extruded master alloy was shown in figure 1(b) and (c). The Mg matrix was stretched along the direction of extrusion stress. The Mg-Y phases were broken up.
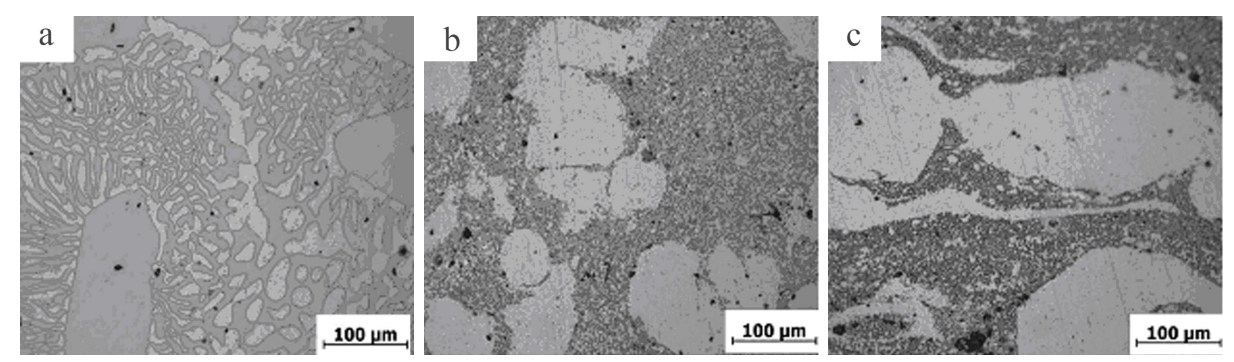

Fig. 1 Microstructures of Mg-25wt. \%Y master alloy; (a) as-cast; (b) extruded, transverse; (c) extruded, longitudinal

From the analysis results of XRD, the phase composition of the as-cast $\mathrm{Mg}-\mathrm{Y}$ master alloy was composed of primary $\alpha-\mathrm{Mg}$ phase and $\beta-\mathrm{Mg}_{24} \mathrm{Y}_{5}$ phase.

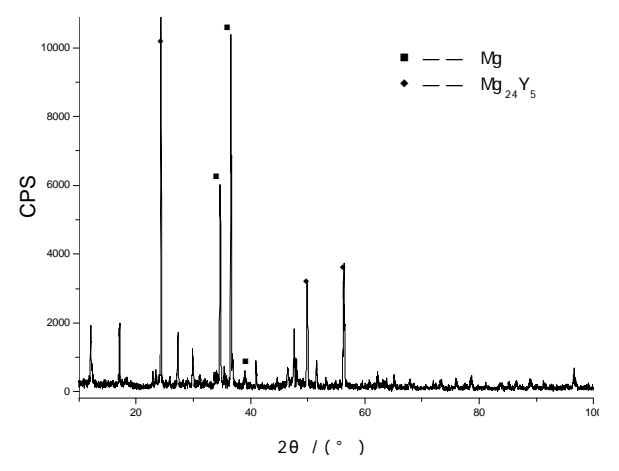

Fig. 2 XRD pattern of As-cast Mg-Y master alloy

When the master alloy was added into the molten, the $\mathrm{Mg}$ matrix molten down and yttrium elements in solid solution in the $\alpha-\mathrm{Mg}$ dissolved in the melt. Meanwhile, the phase diagram of the Mg-Y alloy 
shows that the $\operatorname{Mg}_{24} \mathrm{Y}_{5}$ phase will decompose in about $605^{\circ} \mathrm{C}$ and the $\mathrm{Mg}_{2} \mathrm{Y}$ phase with higher melting point will be generated, the reaction equation is as follows [10]:

$$
M g_{24} Y_{5}(s) \rightarrow L_{1}+M g_{2} Y(s) \quad \text { the reaction temperature is } 605^{\circ} \mathrm{C} \text {. }
$$

The $\mathrm{L}_{1}$ represents the liquid phase. As can be seen from the phase diagram, the content of yttrium in the liquid phase $\left(\mathrm{L}_{1}\right)$ is about $35 \%$. When the $\mathrm{Mg}_{24} \mathrm{Y}_{5}$ phase decomposed into $\mathrm{Mg}_{2} \mathrm{Y}$ phase, the yttrium element dissolved into the melt.

The AZ91D melts contains about $9 w t . \%$ of the Al element. Yttrium element preferentially reacts with $\mathrm{Al}$ to generate the Al-Y phase because the difference in electronegativity between yttrium and $\mathrm{Al}$ is greater than that between yttrium and $\mathrm{Mg}$ [11].

The $\mathrm{Mg}_{2} \mathrm{Y}$ phase became solid particles floating in the melt, and gradually sank in magnesium melt.

\section{Microstructures of AZ91D with addition of yttrium in various ways}

The microstructures of as-cast AZ91D with addition of dollop-like yttrium are shown in Fig. 3. In this experiment, the AZ91D alloy melts and holds $30 \mathrm{~min}$ at $750^{\circ} \mathrm{C}$ and the dollop-like yttrium was added into. It can be seen from figure 3(a) that the dollop-like yttrium didn't dissolved completely. In figure 3(a), the area of the A was the yttrium not molten, the area of the B was mainly composed of cluster compounds, the area of the $\mathrm{C}$ was mainly composed of $\alpha-\mathrm{Mg}$ matrix and a large number of polygons Al-Y compound particles and the area of the D was composed of the $\alpha-\mathrm{Mg}$ matrix, the fine dispersed $\mathrm{Mg}_{17} \mathrm{Al}_{12}$ and a large number of Al-Y compounds. Adding the dollop-like yttrium directly into the cast smelting furnace, the Al-Y compound particle was coarse and uneven distribution, which resulted the mechanical properties of magnesium alloy to reduce.
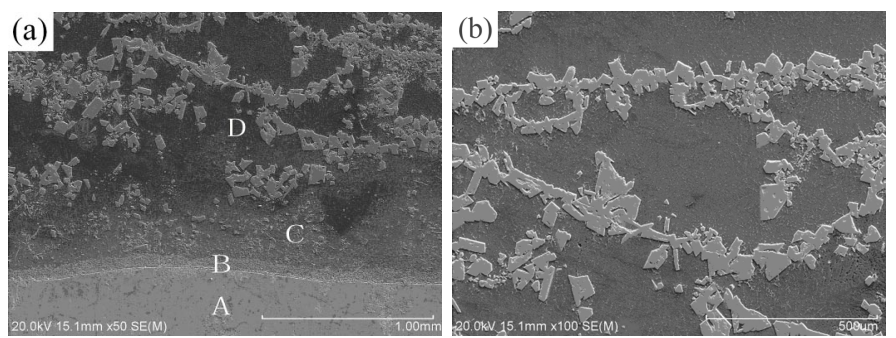

Fig. 3 Microstructures of as-cast with addition of dollop-like yttrium (a) General morphology; (b) D zone morphology

The microstructures of as-cast AZ91D with addition of the as-cast $\mathrm{Mg}$-Y master alloys are shown in Fig. 4. It can be seen that as-cast AZ91D-0.82\% Y alloy was composed of $\mathrm{Mg}_{17} \mathrm{Al}_{12}$ compounds and $\mathrm{Al}_{2} \mathrm{Y}$ phase, as shown in Fig.4 (b). The $\mathrm{Al}_{2} \mathrm{Y}$ particles dispersed in $\mathrm{Mg}$ matrix without apparent aggregation phenomenon.
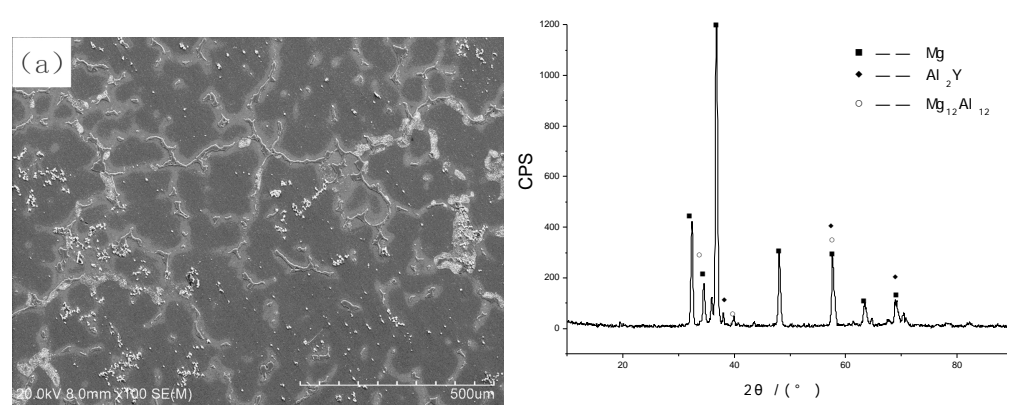

Fig. 4 Microstructures of as-cast AZ91D with addition yttrium by as-cast master alloy;(a) SEM picture of as-cast AZ91D-0.82\% Y; (b) XRD of as-cast AZ91D-0.82\%Y

The microstructure of the as-cast AZ91D with addition of the extruded $\mathrm{Mg}$-Y master alloys is shown in Fig. 5. It can be seen that the microstructure of as-cast AZ91D-0.90\%Y alloy with addition of the extruded Mg-Y master alloy was similar to that of as-cast AZ91D-0.82\%Y alloy with addition of 
the as-cast Mg-Y master alloy. Compared with the as-cast Mg-Y master alloy, the Mg-Y particle in the extruded master alloy was finer. Therefore, the large compound particle didn't be observed in the microstructure of AZ91D-0.9\% Y alloy.

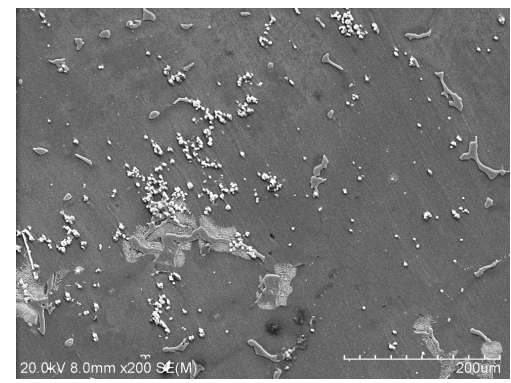

Fig. 5 SEM morphology of as-cast AZ91D with addition yttrium by extruded master alloy

\section{Conclusions}

(1) When AZ91D alloys were melted in an electric resistance furnace and the dollop-like yttrium was added to the melt held for $60 \mathrm{~min}$ at $750^{\circ} \mathrm{C}$, the efficiency of alloying achieved less than $50 \%$.

(2) The Mg-25wt. \%Y master alloy was prepared by permanent mould casting and then was extruded into the bars. The microstructure of as-cast Mg-25wt. \% Y master alloy was composed of $\alpha-\mathrm{Mg}$ matrix and $\mathrm{Mg}_{24} \mathrm{Y}_{5}$ phase. After hot extrusion deformation, the $\mathrm{Mg}_{24} \mathrm{Y}_{5}$ phase was fractured and formed into fine particles, which resulted in an increase in the number of nucleating sites for $\mathrm{Mg}$.

(3) When the melting temperature was $750^{\circ} \mathrm{C}$, the as-cast and extruded Mg-25wt. \% Y master alloy was added into the AZ91D melt and the efficiency of alloying was $71.3 \%$ and $78.3 \%$, respectively. The reason is that the $\mathrm{Mg}$ matrix of the master alloy was dissolved, firstly, and $\mathrm{Mg}_{24} \mathrm{Y}_{5}$ phase dispersed into the melt and was decomposed into $\mathrm{Mg}_{2} \mathrm{Y}$ phase. After extrusion, $\mathrm{Mg}_{24} \mathrm{Y}_{5}$ phase was broken into smaller particles. The finer the particle size was, the slower the settling velocity, and the efficiency of alloying of yttrium was increased.

\section{Acknowledgment}

This project is supported by the Natural Science Foundation of Inner Mongolia Autonomous Region of China [2014MS0517].

\section{References}

[1] G.D. Tong, H.F. Liu, Y.H. Liu, Effect of rare earth additions on microstructure and mechanical properties of AZ91 magnesium alloys, Transactions of Nonferrous Metals Society of China. 20(2010) s336-s340.

[2]B. Hossein, S. Ehsan, Effect of rare elements addition on thermal fatigue behaviors of AZ91magnesium alloy, Journal of Rare Earths, 27(2009) 255-258.

[3] Z. Zhang, A. Couture, An Investigation of the Properties of Mg-Zn-Al alloys, Scripta Materialia. 39(1998) 45-53.

[4] G.Y. Zhang, H. Zhang, M. Gao, D. Wei, Mechanism of effects of rare earths on microstructure and properties at elevated temperatures of AZ91 magnesium alloy, Journal of Rare Earths, 25(2007) 348-351.

[5] S.C. Zhang, B.K. Wei, Q.Z. Cui, Effect of mischmetal and yttrium on the structures and mechanical properties of $\mathrm{Mg}-\mathrm{Al}$ alloy, Transactions of Nonferrous Metals Society of China, 1(2003) 83-87. 
[6] M.X. Wang, H. Zhou, L. Wang, Effect of yttrium and cerium addition on microstructure and mechanical properties of AM50 magnesium alloy, Journal of Rare Earths, 25(2007) 233-237.

[7] W.Z. Liang, Z.L. Ning, H.B. Wang, H.D. Liu, H.H. Liu, Effect of yttrium on microstructures and properties at elevated temperature of $\mathrm{Mg}-0.8 \mathrm{Zr}-0.35 \mathrm{Zn}$ alloys, Journal of Rare Earths, 22(2004) 268-271.

[8] Y.G. Li, S.R. Liu, Effect of yttrium on microstructures of magnesium alloy Mg-Zn-Zr, Journal of Rare Earths, 22. Suppl. (2004) 112-116.

[9] Z. Liu, K. Zhang, X.Q. Zeng, Theory and Application of Mg-based Light Alloy, first ed., China Machine Press, Beijing, 2002.

[10]T.B. Massalski, H. Okamoto, P.R. Subramanian, Binary Alloy Phase Diagrams, 2nd ed., ASM International, USA, 1988

[11]J.C. Xie, Q.A. Li, X.Q. Wang, J.H. Li, Microstructure and mechanical properties of AZ81 magnesium alloy with $\mathrm{Y}$ and Nd elements, Transactions of Nonferrous Metals Society of China, 18(2008) 303-308. 